\title{
The upper-mantle transition zone beneath the Ibero-Maghrebian region as seen by teleseismic Pds phases
}

\author{
Luciana Bonatto (1,2), Martin Schimmel (3), Josep Gallart (3), and José Morales (2) \\ (1) Istituto Nazionale di Geofisica e Vulcanologia, Italy (albonatto@gmail.com), (2) Instituto Andaluz de Geofisica, UGR, \\ Granada, Spain., (3) Institute of Earth Sciences Jaume Almera, CSIC, Barcelona, Spain.
}

We investigate the upper-mantle transition zone thickness beneath the Ibero-Maghrebian region using teleseismic events recorded at 258 seismic stations from the IberArray of the Spanish TopoIberia project. For this purpose, the $410 \mathrm{~km}$ and $660 \mathrm{~km}$ depth discontinuities are mapped through the detection of P-to-s conversions. In order to add consistency and robustness to the detections, the final results are based on a joint analysis of receiver functions and two different cross-correlation functionals. Discontinuity depths are determined using time corrections obtained from a 3-D velocity model. This study presents the first high-resolution topography maps for the 410 and 660 discontinuities, which show lateral variations in the transition zone thickness beneath the study area. The results are discussed to add new constraints on temperature and composition to seismic velocity anomalies observed in the transition zone beneath the controversial Ibero-Maghrebian region. We obtained a thickened transition zone beneath the Alboran Sea and the north Balearic Sea suggesting low transition zone temperatures, and coinciding with the position of the high-velocity anomalies in the tomographic images related to the Betic-Alboran slab and the Alpine-Tethys remnant slab, respectively. A dominantly thinned transition zone beneath the Gulf of Cadiz and its surroundings suggest high-mantle temperatures. We also found evidences of the presence of a low-velocity layer atop the 410 discontinuity beneath the study area. 